\title{
Conformation of Adjacent Self-expanding Stents: A Cross-Sectional In Vitro Study
}

\author{
Marion Hughes, Andrew R. Forauer, Mats Lindh, ${ }^{*}$ Wojciech Cwikiel
}

Section of Vascular \& Interventional Radiology, University of Michigan Medical Center, Ann Arbor, Michigan, USA

\begin{abstract}
We examined the proximal conformation of three commonly used self-expanding stents when the stents were deployed adjacent to one another in a tubular model, simulating a "kissing" stent technique. The stent pairs were evaluated by computed tomogrphy to determine the crosssectional area excluded by the stents within the model. The mean areas associated with each stent pair were compared and significance evaluated by a $t$-test. A statistically significant difference was found when the area excluded by adjacent Wallstents was compared with both the Luminexx and SMART stents $(p<0.001$ and $p<0.002$, respectively). The difference in the area excluded and differences in conformation might play a role in the lower patencies that have been observed in "kissing" stent series.
\end{abstract}

Key words: Stents-Interventional procedures

Percutaneous reconstruction of the aortic bifurcation using a "kissing" stent technique has been described as a treatment option in the setting of stenosis or occlusion [1,2]. Reported patency rates of these stents in several series are lower [3-5] than either isolated aortic [6] or iliac stents [7, 8]. Many in vitro characteristics of various stent designs have been explored in an attempt to determine the optimal device for given clinical settings [9-13]. We examined the proximal conformation of three different self-expanding stents deployed using a "kissing" stent technique in a simple tubular model with cross-sectional imaging. The results are

This work was presented at the Society of Interventional Radiology Annual Scientific Meeting, March 2004, Phoenix AZ.

* Present address: Radiology Department, University Hospital MAS, SE20502 Malmö, Sweden

Correspondence to: Andrew R. Forauer, M.D., Vascular Interventional Radiology, Dartmouth-Hitchcock Medical Center, One Medical Center Drive, Lebanon, NH 03756, USA; email: andrew.r.forauer@hitchcock.org discussed in relation to the postulated theories for the clinical experiences of decreased patency.

\section{Methods}

Three commonly used self-expanding stent designs were selected for evaluation: Wallstent (Boston Scientific, Natick, MA), Luminexx (CR Bard, Covington, GA), and SMART (Cordis, Miami, FL) (Fig. 1). Ten-millimeter-diameter stents were chosen based on the previous clinical experience of the authors and historical evidence in the literature as a common stent diameter in treating common iliac artery stenoses and occlusions. The stent dimensions were as follows: Wallstent, $10 \mathrm{~mm} \times 42 \mathrm{~mm}$; Luminexx, $10 \mathrm{~mm} \times$ $60 \mathrm{~mm}$; SMART, $10 \mathrm{~mm} \times 60 \mathrm{~mm}$.

The stents were deployed simultaneously within a polypropylene plastic tube that was rigid and symmetrically round (diameter: $15.2 \mathrm{~mm}$; length: $76 \mathrm{~mm}$ ). The stents and model were then immersed in a $37^{\circ} \mathrm{C}$ water bath to simulate body temperature and facilitate an accurate conformation of the nitinol stents. The stent pairs were allowed to remain in the water bath for a minimum of 5 min prior to imaging. Imaging was also performed with the stent pairs in the water bath.

Computed tomography (CT) imaging was performed using a multidetector CT (GE Light Speed, 8-slice scanner; GE Medical Systems, Milwaukee, WI). Imaging parameters are as follows: slice thickness, $1.25 \mathrm{~mm}$; slice interval, $5 \mathrm{~mm}$; kvP, 100; MA, 80; Dfov, $9.6 \mathrm{~cm}$. An initial longitudinal scout image was obtained to document accurate stent deployment at the same level. Four contiguous axial images were then obtained to evaluate the shape and conformation of the stents. The images were then transferred to a computer workstation (GE Advantage/Windows 4.0; GE Medical Systems; Milwaukee, WI) to determine the area excluded by the stent pairs.

At the workstation, one of the axial CT images was selected and windowed appropriately to allow the operator to (1) visualize the inner wall of the model and (2) determine the outer margin of each stent pair. Using a free-hand technique, the area excluded by the stents was drawn using the workstation's mouse (Fig. 2). The workstation software provided a calculated area $\left(\mathrm{mm}^{2}\right)$ for each region of interest that was drawn. The two areas were summed to provide the total area excluded for each deployed pair. The regions were redrawn five separate times for each pair, and this task was performed by the same author for consistency of tracing methodology. 

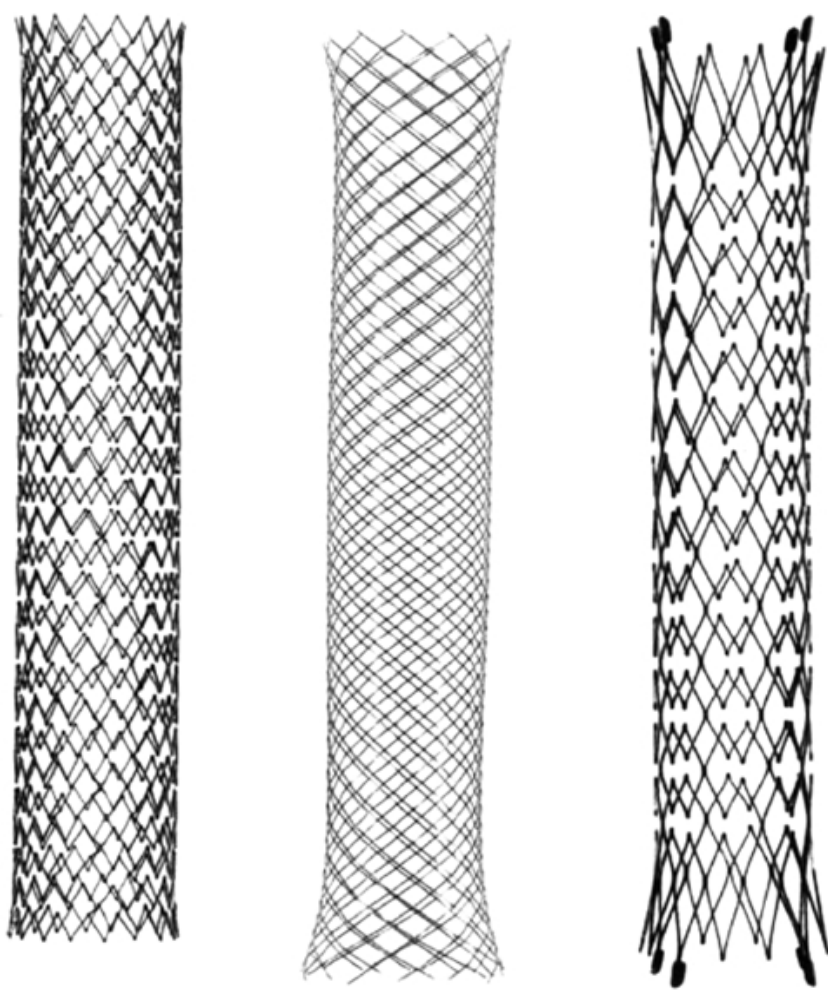

Fig. 1. Side-by-side comparison of the three stent designs evaluated: (left to right) SMART (Cordis, Miami, FL), Wallstent (Boston Scientific, Natick MA), Luminexx (CR Bard, Covington, GA).

The cross-sectional area of the tube was calculated using the diameter of the model (as measured by digital calipers; area of a circle $=\pi r^{2}$. Each area excluded was also expressed as a percentage [i.e., (area excluded/cross-sectional area of model) $\times 100$ ]. The corresponding percentage of cross-sectional area preserved by the stent lumens was calculated as well $\{[1-$ (area excluded/crosssectional area) $] \times 100\}$.

The stent pairs were deployed three times each. Therefore, each stent pair, being deployed 3 times, and the excluded areas drawn 5 times, yielded 15 values per stent design.

\section{Statistical Analysis}

The mean area excluded was calculated for each stent-pair deployment. These mean values were then compared with the other stent designs using a simple $t$-test (Two-Sample Assuming Unequal Variances). A $p$-value of less than 0.01 was considered to be significant.

\section{Results}

Qualitatively, the cobalt-chromium alloy stent (Wallstent) assumed adjacent circular configurations: a "double-barrel" appearance. There was no flattening of the stent-stent interface. In all cobalt-chromium stent deployments, one stent assumed a visibly larger lumen than the other, despite both stents being of identical diameter and length. Both nitinol designs demonstrated more apposition and flattening along the midline; this was termed a "double D" appearance, as it appeared similar to two adjacent letter "D"s back to back (Fig. 3).

The mean, median, and observed range of the area excluded $\left(\mathrm{mm}^{2}\right)$ by the stents is detailed in Table 1 . The mean area excluded by the Wallstent was $83.5 \mathrm{~mm}^{2}$ (range: $80-87$ ). The mean area excluded for the nitinol designs (Luminexx and SMART respectively) were $47.9 \mathrm{~mm}^{2}$ (range: 43-52) and $45.0 \mathrm{~mm}^{2}$ (range: $40-49$ ). The average percentage of the excluded area and preserved lumen are presented in Table 2. When the area excluded by the cobalt-chromium stent was compared to that of each nitinol design, there was a statistically significant difference $(p<0.001$ for the Luminexx and $p<0.002$ for the SMART stent) (Table 3). No significant difference was found when the area excluded by the two nitinol stent designs were compared to one another $(p=0.23)$.

\section{Discussion}

In general, the reported patency rates of "kissing" iliac stents is lower [3-5] than aortic stents [6], iliac stents [7, 8] or surgical aorto-bifemoral grafts [14]. Possible contributing factors include local thrombus formation, altered hemodynamics, the process of intimal hyperplasia, and physical properties of the stent itself.

As an explanation, some clinicians postulate potential thrombus formation arising from the midline interface between two opposing stents [2]. There are two interrelated factors that potentially contribute to an increased risk of thrombogenicity. One is the inherent physical properties of the stent itself. A review of this topic by Palmaz [15] discusses the role of physical stent characteristics such as surface roughness of the metal alloy, the surface charge of the alloy, and the free-surface energy (surface tensions) of the material and how these can affect the rate and degree of thrombus formation on the newly deployed stent. These properties, in turn, influence the rate of stent endothelialization.

The second is the inherent coagulation system of the patient. All three elements of Virchow's triad are potentially present when a patient with bifurcation atherosclerotic disease undergoes "kissing" stent placement. Endothelial damage is intimately associated with atherosclerotic vascular disease. Frank stasis, or, at the very least, disturbed flow, has been shown following kissing stent deployment, as discussed earlier [9, 16]. Finally, at least local alteration in the coaguable environment can be assumed with the presence of metallic endoprotheses.

A description of the histopathologic examination of early, failed "kissing" stents describes the stents as containing a web of gelatinous appearing tissue [17]. Microscopically, this web was composed of smooth muscle cells in a collagenous background matrix. The authors concluded that altered flow dynamics in the treated segment, caused by 


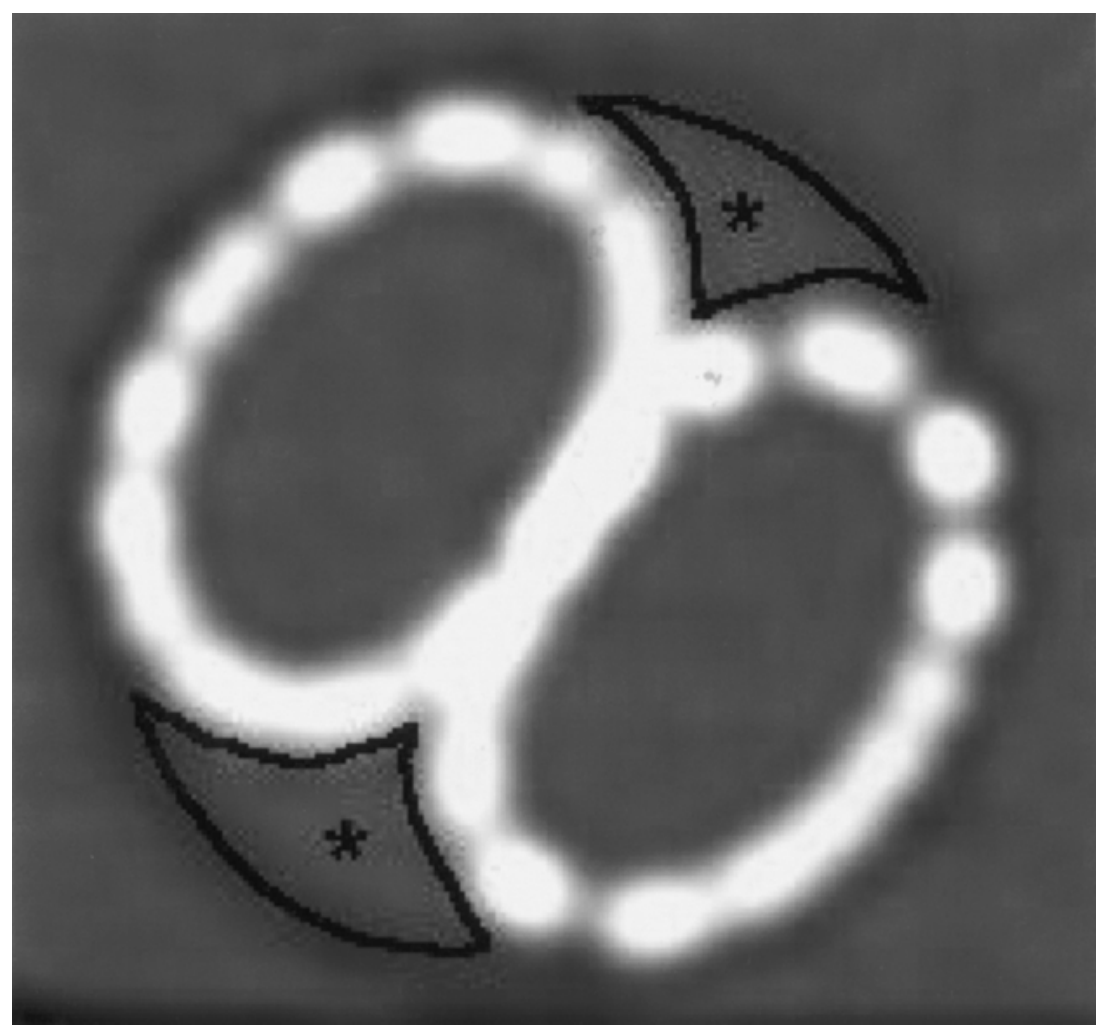

Fig. 2. Example of excluded area (marked by asterisks) drawn on the CT image for measurement. diameter differences (10 mm left, $12 \mathrm{~mm}$ right) as well as flow alterations adjacent to the stents, were responsible for accelerated intimal hyperplasia and failure.

Detailed examinations of blood flow at bifurcations have been performed using both computer simulations and in vitro circuit models [18-20]. In a nonelastic, glass model of the human aorta with steady-state flow, areas of slowed and stagnant flow can be identified [18]. In addition, secondary flow patterns (vortices) were observed under simulated resting conditions.

The hemodynamics in a pulsatile flow model of the infrarenal aorta change during the cycle of systole-diastole. At peak systole, flow is not disturbed or turbulent; whereas at mid-diastole (the point of slowest blood velocity), there are areas of turbulent flow along the outer or lateral aspect of the flow column [9]. Localized changes in flow can and do occur with varying angles of the bifurcation [21], the degree of curvature of the infrarenal aorta in the anteriorposterior (A-P) dimension [20], changing from the resting to the exercise state $[18,20]$ as well as within the cardiac cycle itself. The flow of blood in the distal infrarenal aorta can not only be altered, but small areas of frank stagnation have been confirmed at the level of the posterior wall near the bifurcation in the exercise state [20].

The introduction of unilateral or bilateral stents adds yet another variable to the list of parameters that can alter flow. In Saker's abstract under steady-state flow conditions, glass beads were injected into the model to assist with visualization of flow [16]. These beads were shown to accumulate in the space between the kissing stent vertex and the model's flow divider. The authors went on to report the lack of observed laminar flow following the kissing stent deployment.

There is a relationship between blood flow and observed intimal hyperplasia. A decrease in blood flow (i.e., low shear stress) has been associated with increased neointimal thickening in the anastomotic region of synthetic bypass conduits. Conversely, a high-shear-stress environment can inhibit or even initiate regression of neointimal thickening [22]. Similar observations have also been shown in vein bypass grafts [23]. More importantly, decreased blood flow through a stented vessel segment has been shown to promote neointimal hyperplasia [24].

The materials used in the manufacturing of the stents are partly responsible for our observations. The self-expanding properties of the Wallstent are a result of a spiral construction with a mesh of longitudinal wire strands. Stents made of nitinol depend on shape memory of the material. Shape memory is the property of nitinol where an initial shape is re-formed or restored at a temperature level predetermined in the manufacturing process [25]. It is the characteristic that is responsible for the return to a circular cross section after deployment of a nitinol stent. In addition, continued expansion force (radial force) is generated in the drive to return to the original unconstrained diameter. This characteristic contributes to the observed flattening of the stent-stent interface, resulting in the "double D" appearance. 

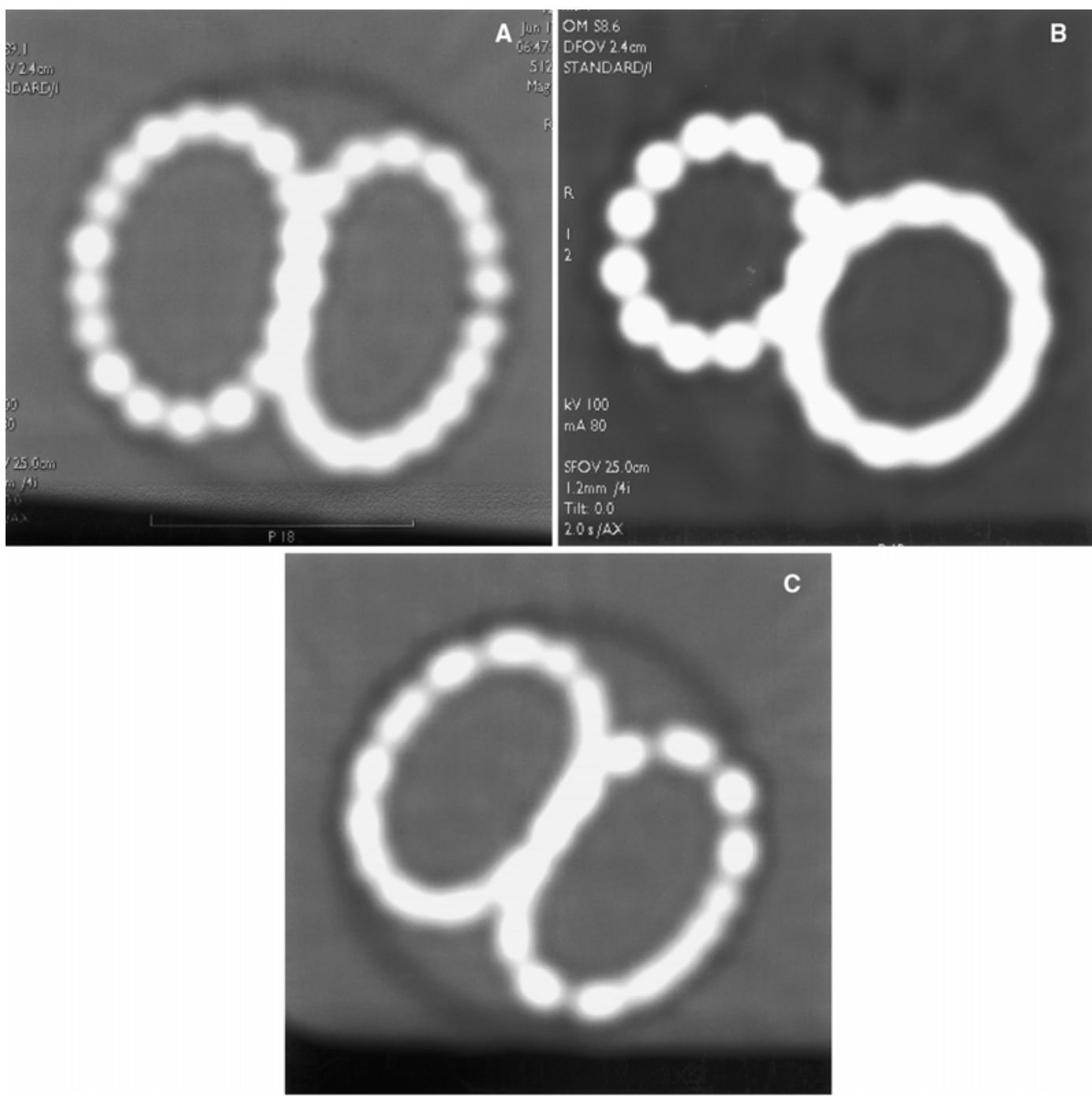

Fig. 3. Transverse CT image of each stent pair evaluated. Note the difference in configuration between the two nitinol stents (a and c) and the cobalt-chromium alloy stent (b). (a) SMART; (b) Wallstent; (c) Luminexx.

Table 1. Areas excluded by the stent pairs

\begin{tabular}{llll}
\hline & $\begin{array}{l}\text { Mean area } \\
\text { excluded } \\
\left(\mathrm{mm}^{2}\right)\end{array}$ & $\begin{array}{l}\text { Median area } \\
\text { excluded } \\
\left(\mathrm{mm}^{2}\right)\end{array}$ & $\begin{array}{l}\text { Observed } \\
\text { range } \\
\left(\mathrm{mm}^{2}\right)\end{array}$ \\
\hline Wallstent & 83.5 & 84 & $80-87$ \\
Luminexx & 47.9 & 48 & $43-52$ \\
SMART & 45.0 & 46 & $40-49$ \\
\hline
\end{tabular}

Table 2. Percent of transverse area excluded and included for each stent pair

\begin{tabular}{lll}
\hline & $\%$ Area excluded & $\%$ Area included \\
\hline Wallstent & 46 & 54 \\
Luminexx & 26 & 74 \\
SMART & 25 & 75 \\
\hline
\end{tabular}

The radial strength of stents can vary at different degrees of stenosis across a curved vessel segment [12]. In addition, cell design has also been shown to affect stent expansion
Table 3. Comparison of area excluded by stent type

\begin{tabular}{lcl}
\hline & Difference $\left(\mathrm{mm}^{2}\right)$ & Significance \\
\hline Wallstent vs. SMART & +38.5 & $p<0.002$ \\
Wallstent vs. Luminexx & +35.6 & $p<0.001$ \\
SMART vs. Luminexx & -2.9 & $p=0.23$ \\
\hline
\end{tabular}

and configuration. Comparisons of the physical characteristics of self-expanding stents (hoop strength and radial force) have shown conflicting results. Dyet et al. [11] observed that the Wallstent had a greater hoop strength than nitinol stents. These findings were contradicted in another study in which it was observed that the SMART stent (in addition to other nitinol designs) showed better performance than the Wallstent [10].

Our study shows that the different configuration of two adjacent stents can result in varying amounts of excluded 
cross-sectional area. This can approach $50 \%$ in one of the stent designs evaluated. This region can theoretically increase the possibility of thrombus formation and the development of intimal hyperplasia due to slowed and turbulent blood flow. Stents constructed of nitinol displayed more apposition in the midline. This "double D" conformation reduced the excluded space compared to the "double barrel" appearance of the cobalt-chromium metallic stent, simultaneously preserving a greater portion of the model's lumen for flow patterns that are less disturbed. These findings indicate that placement of "kissing" nitinol stents in aortic bifurcation disease might yield better patencies and clinical outcomes.

An admitted limitation of this study was the use of a rigid polypropylene model without pulsatile flow. It was our intention to focus on the behavior of two adjacently deployed stents and how this affected their conformation with one another. Further investigation of the effect in a flow model constructed from a more compliant material could help guide the choice of devices for placement at the aortic bifurcation even further.

\section{References}

1. Kuffer G, Spengel F, Steckmeier B (1991) Percutaneous reconstruction of the aortic bifurcation with Palmaz stents: Case report. Cardiovasc Interent Radiol 14:170-172

2. Palmaz JC, Encarnacion CE, Garcia OJ, et al. (1991) Aortic bifurcation stenosis: Treatment with intravascular stents. J Vasc Intervent Radiol 2:319-323

3. Brittenden J, Beattie G, Bradbury AW (2001) Outcome of iliac kissing stents. Eur J Vasc Endovasc Surg 22:466-468

4. Haulon S, Mounier-Vehier C, Gaxotte V, et al. (2002) Percutaneous reconstruction of the aortoiliac bifurcation with the "kissing stents" technique: Long-term follow-up in 106 patients. J Endovasc Ther 9:363-368

5. Mohamed F, Sarker B, Timmons G, et al. (2002) Outcome of "kissing stents" for aortoiliac atherosclerotic disease, including the effect on the non-diseased contralateral iliac limb. Cardiovasc Intervent Radiol 25:472-475

6. Long AL, Gaux JC, Raynaud AC, et al. (1993) Infrarenal aortic stents: Initial clinical experience and angiographic follow-up. Cardiovasc Intervent Radiol 16:203-208

7. Henry M, Amor M, Ethevenot G, et al. (1995) Palmaz stent placement in iliac and femoropopliteal arteries: Primary and secondary patency in 310 patients with 2-4 year follow-up. Radiology 197:167174

8. Vorwerk D, Gunther RW, Schurmann K, et al. (1996) Aortic and iliac stenoses: Follow-up results of stent placement after insufficient balloon angioplasty in 118 cases. Radiology 198:45-48

9. Fabregues S, Baijens K, Rieu R, et al. (1998) Hemodynamics of endovascular prostheses. J Biomech 31:45-54

10. Duda S, Wiskirchen J, Tepe G, et al. (2000) Physical properties of endovascular stents: An experimental comparison. J Vasc Intervent Radiol 11:645-654

11. Dyet JF, Watts WG, Ettles DF, et al. (2000) Mechanical properties of metallic stents: How do these properties influence the choice of stent for specific lesions? Cardiovasc Intervent Radiol 23:47-54

12. Kalmar G, Hubner F, Voelker W, et al. (2002) Radial force and wall apposition of balloon expandable stents in eccentric stenoses: An in vitro evaluation in a curved vessel model. J Vasc Intervent Radiol 13:499-508

13. Poerner TC, Ludwig B, Duda SH, et al. (2004) Determinants of stent expansion in curved stenotic lesions: An in vitro experimental study. J Vasc Intervent Radiol 15:727-735

14. De Vries SO, Hunink MGM (1997) Results of aortic bifurcation grafts for aortoiliac occlusive disease: A meta-analysis. J Vasc Surg 26:558-569

15. Palmaz JC (1993) Intravascular stents: Tissue-stent interactions and design considerations. Am J Roentgenol 160:613-618

16. Saker MB, Gordon G, Ryu RK, et al. (2001) The effect of "kissing" aorto-iliac stents on laminar blood flow. 26th Annual Scientific Meeting, SCVIR, San Antonio, TX, March 6, 2001 (abstract)

17. Saker MB, Oppat WF, Kent SA, et al. (2000) Early failure of aorto-iliac kissing stents: Histopathologic correlation. J Vasc Intervent Radiol 11:333-336

18. $\mathrm{Ku} \mathrm{DN}$, Glagov S, Moore JE, et al. (1989) Flow patterns in the abdominal aorta under simulated postprandial and exercise conditions: An experimental study. J Vasc Surg 9:309-315

19. Wong PKC, Eng B, Johnston KW, et al. (1991) Computer simulation of blood flow patterns in arteries of various geometries. J Vasc Surg 14:658-657

20. Pedersen EM, Yoganathan AP, Lefebvre XP (1992) Pulsatile flow visualization in a model of the human abdominal aorta and aortic bifurcation. J Biomech 25:935-944

21. Friedman MH, Deters OJ, Mark FF, et al. (1983) Arterial geometry affects hemodynamics. Atherosclerosis 46:225-231

22. Mattsson EJR, Kohler TR, Vergel SM, et al. (1997) Increased blood flow induces regression of intimal hyperplasia. Arterioscler Thromb Vasc Biol 17:2245-2249

23. Morinaga K, Okadome K, Kuroki M, et al. (1985) Effect of wall shear stress on intimal thickening of arterially transplanted autogenous veins in dogs. J Vasc Surg 5:430-433

24. Richter GM, Palmaz JC, Noeldge G, et al. (1999) Relationship between blood flow, thrombus, and neointima in stents. J Vasc Intervent Radiol 10:598-604

25. Rabkin DJ, Lang EV, Brophy DP (2000) Nitinol properties affecting uses in interventional radiology. J Vasc Intervent Radiol 11:343-350 